\title{
Research on social determinants of health necessary for health equity in India
}

Public health care in India in the last nearly seven decades since independence has been largely through the various national health programs targeting the major health-related problems and issues. The progress so far in improving the health indicators has also been impressive in most areas. Life expectancy has increased from 32 years at the time of independence to 65 years in 2012. ${ }^{[1]}$ The reductions in maternal and infant mortality are also remarkable; maternal mortality ratio having decreased from 398/lakh live births in 1991 to 167 / lakh live births in 2013 and infant mortality rate down from 140/1000 live births in 1976 to 40/1000 in 2013..$^{[2-4]}$ However, the pace of decline in mortality and improvement in other indicators, which was faster in the earlier decades, has now slowed down. ${ }^{[5]} \mathrm{It}$ is expected that further decline in the rates will be slower and more difficult to achieve.

There are other areas where our achievement has been very minimal, for example, under-nutrition among children. The proportion of underweight under-five children in India having decreased marginally from $43 \%$ to $40 \%$ from the second to third round of National Family Health Survey (NFHS) between years 1998-1999 and 2005-2006. ${ }^{[6,7]}$ Even in a well-performing state like Tamil Nadu, the proportion went down from 31.5 to 29.8 to 23.8 during NFHS rounds two, three, and four, respectively; the percentage decline being $5 \%$ between second and third and 20\% between third and fourth. ${ }^{[6-8]}$ Whatever the gains in public health has been achieved through the health programs in India, have so far been provider driven. The focus has been on providing medical care and increasing the access of people to advances in medical technology both in preventive and curative medicine. Community participation has been highlighted time and again but only to improve utilization of these services. The initiative for the programs is from the health system, mainly public and has had little to do with the needs and priorities of the people.

\section{NEED TO ADDRESS SOCIAL DETERMINANTS OF HEALTH FOR HEALTH PROMOTION}

The success from these health system driven programs in spite of the health gains has not translated into the communities becoming empowered and responsible of their own health. We have also not been able to reduce the wide disparities in health between different sections of the population and between different regions of the country. The proportion of underweight among under-five children was reported to be nearly 3 times higher, i.e., $56.6 \%$ among the lowest wealth quintile compared to $19.7 \%$ among wealthiest quintile during 2005-2006 (NFHS-3); among children in rural areas, it was $45.6 \%$ versus $32.7 \%$ in the urban areas. ${ }^{[6]}$ The radical change in health policy envisioned by the present government in the form of National Health Assurance Mission is an attempt to reduce these intergroup and regional differences in health status and bring equity in health through Universal Health Care. ${ }^{[9]}$ To address equity, we need a quantum shift in our focus from providing medical care to the sick to imparting skills and bringing about behavioral change to finally enabling people to increase control over the determinants of health and thereby improve their health. The process of enabling people is considered by World Health Organization (WHO) as Health Promotion defined by Ottawa Charter for Health Promotion as "a comprehensive social and political process, not only embracing actions directed at strengthening the skills and capabilities of individuals, but also actions directed toward changing social, environmental, and economic conditions so as to alleviate their impact on public and individual health." ${ }^{[10]}$ To bring about this change, the underlying principles of health promotion, which were promulgated, state that people without power have as much capacity as the powerful to assess their own needs because they are the ones experiencing the problems. Moreover, to be able to do this, the disadvantaged people need to be empowered, not just enabled. Empowerment is the process, that can neither be purely from within or that can be done to others, but a combined effort to bring about greater equality in resources, status, and authority. ${ }^{[10]}$ The unequal distribution of these in our society is being addressed as the Social Determinants of Health (SDH). Therefore, as per WHO, health promotion is about actions particularly directed toward the social, environmental, and economic conditions that support health. ${ }^{[10,11]}$

\section{SOCIAL DETERMINANTS OF HEALTH IN INDIAN HEALTH POLICIES AND PROGRAMS}

WHO's Commission on SDH (CSDH) defines SDH as "the conditions in which people are born, grow, live, work, and age including the health system." "[11] The commission report reiterated the fact that health cannot be achieved by medical care alone and social factors are equal, if not more important. Both the medical community and the policy makers in India had always underestimated the importance of the SDH on the health status of the population until the report of CSDH came in 2008. Even then the High-Level Expert Group that was instituted by the Planning Commission to look into the Universal Health Coverage (UHC) for India, did not have SDH in its terms of reference. The group, however, realized 
that it will be difficult to attain and sustain UHC without action on the wider SDH and added a section on SDH in its report in 2011. ${ }^{[12]}$ The document highlights the important SDH and their role in the inter-state differences in health status of people in India. The groups' recommendations included setting up of Social Determinants Committees at the national, state, and district levels and adding SDH in the mandate of the proposed National Health Promotion and Protection Trust. Although such a trust has not been constituted till date, realizing the importance of the role played by social and environmental determinants in promoting the health of the population, draft National Health Policy (NHP) 2015 mentions this as the second of the policy prescriptions (NHP 2015). The seven priority areas identified in the policy are sanitation, diet, substance abuse, rail and road safety, gender violence, workplace safety, and air pollution. However wherever actions are recommended, these are mostly for the government to take. The vision to enable and empower people for taking their health into their own hands is missing in this document too. This paternalistic attitude stems from the belief that the vast majority of the rural population and the illiterate and less educated people are incapable of deciding what is good for their own welfare.

\section{HEALTH EQUITY AND EMPOWERMENT THROUGH SOCIAL DETERMINANTS OF HEALTH}

This lack of empowerment of large sections of the society including women and the rural populace is one of the reasons for the slow decline in infant mortality rate and maternal mortality ratio in India and the nonachievement of Millennium Development Goal targets for these ${ }^{[13]}$ Noncommunicable diseases are increasing at an alarming rate with an already huge unfinished agenda of controlling infectious disease. This is closely related to the widely prevalent maternal and child under-nutrition which results from a complex interplay of social and health system related factors. To be able to make further dent into the disease burden in India, social, environmental, and behavioral factors are to be addressed along with the changes in the health system. Compared to providing medical services, social, and behavioral changes are more difficult to bring about. This requires an in-depth understanding of the health-related human behavior and social factors that determine them. Social dynamics are very complicated in the Indian context as there are stratifications based on caste, socio-economic status, and gender, the extent of which varies from state to state and between the regions. The major challenge in bringing equity in health is to remove the gaps in the health status between the different strata of the society. For example, the Infant Mortality Rate during the third round of NFHS was 55.7/1000 live births among the forward castes, whereas it was 61.1, 63.9, and 71 among the Other Backward castes, Scheduled tribes and Scheduled Castes, respectively. ${ }^{[6]}$ The reason for such disparity is poor access to resources that improve health among the socially disadvantaged groups like people belonging to the scheduled castes and backward castes. Among the resources that improve health, financial security contributes to health directly and indirectly through other SDH.
According to the NFHS-3 report, there was $35.6 \%$ of the other caste population in the highest wealth quintile whereas there were $15.6 \%, 10.2 \%$, and $5.2 \%$ of the backward castes, scheduled caste and scheduled tribe population respectively in this quintile. Access to health services like institutional deliveries also varied widely with $51 \%$ of the mothers in other castes having delivered in institutions compared to $37.7 \%$ and $32.9 \%$ among the other backward castes and scheduled castes, respectively; and only $17.7 \%$ of the scheduled tribe mothers (NFHS-3). ${ }^{[6]}$ Many such social groups in India face "social exclusion" ${ }^{[14]}$ and, therefore, experience poor health status exhibited by the worse health indicators among them. Many health programs including Reproductive and Child Health in India are now targeting these vulnerable population in an attempt at providing vertical equity. However, in all these approaches, there still persists the paternalistic attitude wherein health functionaries decide the needs, outcomes and strategies or methods, the beneficiaries hardly ever being consulted during the planning process. About the impact of social exclusion on maternal and child health K. R. Nayar states thus "given the cultural and social norms attached to pregnancy, childbirth and child rearing, the best possible pathway for the health programs is through the women themselves. These could be through focused action with women's participation as against targeted interventions imposed from above." ${ }^{[14]}$ This process of women's empowerment can happen through a comprehensive social and political process with initiatives from the government, academia and civil society to understand the SDH, the process in which these interact with each other to cause ill-health and the social interventions at different levels that will produce sustainable improvements in the health of the people and promote health. This branch of medicine dealing with the social aspects of health and disease is known as medical sociology.

\section{NEED FOR SOCIAL EPIDEMIOLOGICAL RESEARCH IN HEALTH}

Medical sociology is a much-neglected branch of Medicine in India. Although there has been a spate of medical research in India in the recent times, social epidemiological studies are very scant. Identifying multiple risk factors, which include socio-demographic variables for various disease conditions, has not resulted in any change in those conditions among the population. True social-epidemiological studies, which give an in-depth understanding of the SDH for different disease conditions and how they determine people's behavior thereby influencing their health is the need of the hour. Although there are multiple theories explaining what causes human behaviors and their impact on health, these are expounded by social scientists from the west and do not always reflect the complex social scenario in India. India being socially and culturally very different, the individual and social forces that determine the pro-health behaviors and can bring about the success of health programs need to be analyzed in the particular given context. The interventions, which led to increase in the coverage of Pulse Polio immunization in states like Uttar Pradesh finally leading to eradication of poliomyelitis from India, were more social than medical. Intensified social mobilization with the enhanced involvement of religious leaders, 
Muslim institutions, mosques, and madrasas were part of the success story. ${ }^{[15]}$ The Social interventions targeting behavior change cannot be uniform across countries and communities. Therefore, social interventions that have been proven to be effective in other countries or some parts of India may not have an equal impact on the rest of the country. When such interventions are applied for example tobacco control in India for noncommunicable disease control or maternal and child health without studies on their effectiveness, the results might not only be slow, but even unachievable. Therefore, replicating the strategies that have not been generated from research in India may only be a case of wastage of funds in an already resource-constrained country. Epidemiologists in India need to take up both fundamental and applied research in medico-social epidemiology to come up with effective social interventions that can promote health, prevent disease and help in recovery from the diseased state. Behavior change has an equally important role in curative medicine as in preventive and promotive health care as supportive to drug therapeutics and other medical and surgical procedures. Therefore, clinical researchers, epidemiologists and social scientists need to work together on the same platform to conduct observational and interventional research for understanding the health-related behavior among Indians, the social determinants which influence these behaviors and the social interventions, which will work in specific Indian settings. Only then we will be able to influence the medical fraternity and change the mindset of the policy makers. Tackling SDH has been proven to reduce disparities in health. ${ }^{[16]}$ When evidence generated from such studies are utilized, interventions within and outside the healthcare system that address some of the SDH and upstream factors such as housing, neighborhood conditions, and increased socio-economic status that can lead to improvements in health will be reflected in the strategies and recommendations of Indian health programs and policies. ${ }^{[16]}$

\section{Sonali Sarkar}

Department of PSM, JIPMER, Puducherry, India

\section{Address for the Correspondence:} Dr. Sonali Sarkar,

Department of PSM, JIPMER, Puducherry, India. E-mail: sarkarsonaligh@gmail.com

\section{REFERENCES}

1. Pathy MS, Sinclair AJ, Morley JE. Delivery of health care in India. In: Principles and Practice of Geriatric Medicine. Ch. $168,5^{\text {th }}$ ed. Chinchester: John Wiley and Sons; c2006. p. 1983.

2. Maternal Mortality Ratio Bulletin 2011-13. Office of the Registrar General and Census Commissioner, GOI; 2011. Available from: http:// www.censusindia.gov.in/vital_statistics/mmr_bulletin_2011-13.pdf. [Last accessed on 2016 Feb 04].

3. Sample Registration System September 2014 Bulletin. Office of the Registrar General and Census Commissioner, GOI; 2011. Available from: http://www.censusindia.gov.in/vital_statistics/SRS_Bulletins/SRS $\% 20$ Bulletin\%20-Sepetember\%202014.pdf. [Last accessed on 2016 Feb 04].

4. Srinivasan K. Population and development in India since independence: An overview. J Fam Welf 2004;50:6-12.
5. Department of Health and Family Welfare. Annual Report to the People on Health. New Delhi: Ministry of Health and Family Welfare, Government of India; 2011.

6. International Institute for Population Sciences (IIPS) and Macro International. National Family Health Survey (NFHS-3), 2005-06: India. Mumbai: IIPS; 2007.

7. International Institute for Population Sciences (IIPS) and ORC Macro. National Family Health Survey (NFHS-2), 1998-99: India. Mumbai: IIPS; 2000.

8. Key Findings from NFHS-4. National Family Health Survey, India. Available from: http://www.rchiips.org/nfhs/factsheet_NFHS-4.shtml. [Last accessed on 2016 Feb 04].

9. Golechha M. The national health assurance mission for India. Lancet 2014;384:1185-6.

10. Detels R, Gulliford M, Karim QA, Tan CC, editors. Oxford Textbook of Global Public Health. $6^{\text {th }}$ ed., Vol. 2. Oxford, New York: Oxford Textbook; 2015. p. 888.

11. World Health Organization. A Conceptual Framework for Action on the Social Determinants of Health: Debates, Policy and Practice, Case Studies; 2010. Available from: http://www.apps.who.int/iris/ bitstream/10665/44489/1/9789241500852_eng.pdf. [Last cited on 2016 Feb 04].

12. Planning Commission of India. High Level Expert Group Report on Universal Health Coverage. New Delhi: Planning Commission of India, Government of India; 2011.

13. Social Statistics Division. Millennium Development Goals - India Country Report 2015. New Delhi: Ministry of Statistics and Programme Implementation, Government of India; 2015.

14. Nayar KR. India's Country Experience in Experience Addressing Social Exclusion in Maternal and Child $h$ Addressing Social Exclusion in Maternal and Child Health. Paper Presented at: World Conference on Social Determinants of Health, Rio de Janeiro, Brazil; 19-21 October, 2011. p. 26. Available from: http://www.cdrwww.who. int/entity/sdhconference/resources/draft_background_paper8_india. pdf. [Last cited on 2016 Feb 04].

15. The Journey to a Polio-Free; 2010. Available from: http://www. indiaenvironmentportal.org.in/files/file/Polio_Booklet-final_(22-02-2012) V3.pdf. [Last cited on 2016 Feb 04].

16. Williams DR, Costa MV, Odunlami AO, Mohammed SA. Moving upstream: How interventions that address the social determinants of health can improve health and reduce disparities. J Public Health Manag Pract 2008;Suppl 14:S8-17.

This is an open access article distributed under the terms of the Creative Commons Attribution-NonCommercial-ShareAlike 3.0 License, which allows others to remix, tweak, and build upon the work non-commercially, as long as the author is credited and the new creations are licensed under the identical terms.

\begin{tabular}{|c|c|}
\hline \multicolumn{2}{|l|}{ Access this article online } \\
\hline Quick Response Code: & \\
\hline \multirow{2}{*}{ 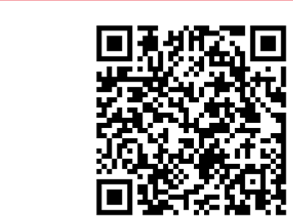 } & $\begin{array}{l}\text { Website: } \\
\text { www.ijmedph.org }\end{array}$ \\
\hline & $\begin{array}{l}\text { DOI: } \\
\text { 10.4103/2230-8598.179752 }\end{array}$ \\
\hline
\end{tabular}

How to cite this article: Sarkar S. Research on social determinants of health necessary for health equity in India. Int J Med Public Health 2016;6:1-3. 